\title{
EXISTENCE OF POSITIVE RADIAL SOLUTIONS FOR A CLASS OF NONLINEAR SINGULAR ELLIPTIC PROBLEMS IN ANNULAR DOMAINS
}

\author{
by ZONGMING GUO
}

(Received 17th May 1990)

We establish the existence of positive radially symmetric solutions of $\Delta u+f\left(r, u, u^{\prime}\right)=0$ in the domain $R_{1}<r<R_{0}$ with a variety of Dirichlet and Neumann boundary conditions. The function $f$ is allowed to be singular when either $u=0$ or $u^{\prime}=0$. Our analysis is based on Leray-Schauder degree theory.

1980 Mathematics subject classification (1985 Revision) $35 \mathrm{~J} 65$.

1.

In this paper we consider the existence of positive radially symmetric solutions of the singular equation

$$
\Delta u+f\left(r, u, u^{\prime}(r)\right)=0 \quad \text { in } R_{1}<r<R_{0}
$$

subject to one of the following sets of boundary conditions

$$
\begin{aligned}
& u=0 \quad \text { on } r=R_{1} \quad \text { and } \quad u=0 \quad \text { on } r=R_{0} \\
& u=0 \quad \text { on } r=R_{1} \quad \text { and } \quad \frac{\partial u}{\partial r}=0 \quad \text { on } r=R_{0} \\
& \frac{\partial u}{\partial r}=0 \quad \text { on } r=R_{1} \quad \text { and } \quad u=0 \quad \text { on } r=R_{0}
\end{aligned}
$$

Here $r=|x|, x \in \mathbb{R}^{N}, N \geqq 3 ; \partial / \partial r$ denotes differentiation in the radial direction; $0<R_{1}<$ $R_{0} \leqq \infty ; f$ is continuous on $\left(R_{1}, R_{0}\right) \times(0, \infty) \times(-\infty, \infty)$. The equation is singular because $f$ is allowed to be singular at $u=0, u^{\prime}=0$ and $r=R_{0}, R_{1}$.

Equation (1.1) arises in many branches of mathematics and applied mathematics. It has been studied by many authors, see for example, [5], [8], [14].

Recently, the problem of the existence of positive radially symmetric solutions of the problem 


$$
\left.\begin{array}{rlc}
\Delta u+f(u)=0 & \text { in } \Omega \\
u=0 & \text { on } & \partial \Omega
\end{array}\right\}
$$

where $\Omega \subset \mathbb{R}^{N}, N \geqq 3$ is a symmetric domain and $f$ is nondecreasing, has attracted much interest and has been treated by many authors (see $[5,9,15-16,10])$. An important contribution was made by Gidas, $\mathrm{Ni}$ and Nirenberg [10] who showed that all positive solutions in $C^{2}(\bar{\Omega})$ of the equation (1.3) are radially symmetric provided that $\Omega$ is a $N$-ball. They also provided that no such result automatically applies to the annulus (see also [13]). On the other hand, when $f(u)$ is superlinear (i.e. $\lim _{t \rightarrow \infty} f(t) / t=\infty$ ) the existence of positive solutions of problem (1.3) with a general $\Omega$ has been provided under various sets of assumptions, always including a restriction on the growth $f$ at infinity (see $[1,4,14]$ ). It is known that such a growth condition is, in general, necessary for starlike domains [18]. In the case of the annulus, such a growth condition is not necessary [2]. Therefore, the problem of the existence of solutions of equation (1.1) in an annulus is of much interest. It is natural to look for radially symmetric solutions because an annulus is a symmetric domain. We easily give many references $([2,6,11-13])$.

We shall study the problems when $f$ depends on $u$ and $u^{\prime}$ and $f$ is nonincreasing for $u$ and $u^{\prime}$. When $f\left(r, u, u^{\prime}(r)\right)=f(u)$ and $f(u)$ is nonincreasing, some results about the existence and uniqueness of a positive radially symmetric solution of the problem (1.1) with the boundary condition (1.2a) has been given in [11].

Putting

$$
\begin{aligned}
t & =\left[(N-2) r^{N-2}\right]^{-1} \\
\phi(t) & =([N-2) t]^{-k} \quad k=(2 N-2) /(N-2) \\
t_{i} & =\left[(N-2) R_{i}^{N-2}\right]^{-1} \quad i=0,1
\end{aligned}
$$

radial solutions of (1.1) are solutions of

$$
u^{\prime \prime}(t)+\phi(t) g\left(t, \dot{u}, u^{\prime}(t)\right)=0 \quad t_{0}<t<t_{1}
$$

(see [2]). Now the boundary conditions become

$$
\begin{array}{lll}
u\left(t_{0}\right)=0 & \text { and } & u\left(t_{1}\right)=0 \\
u^{\prime}\left(t_{0}\right)=0 & \text { and } & u\left(t_{1}\right)=0 \\
u\left(t_{0}\right)=0 & \text { and } & u^{\prime}\left(t_{1}\right)=0
\end{array}
$$

(when $R_{0}=\infty, t_{0}=0$ ). In this, or other equivalent forms, these problems have been investigated by many authors (see $[3,7,11,17]$ ). Our results improve on the results of $[3],[17]$ and cover many new examples not treated by [3], [11], [17]. 
By a solution $u$ of $(1.1)^{\prime}$ we mean $u \in C^{2}\left(t_{0}, t_{1}\right) \cap C^{1}\left[t_{0}, t_{1}\right]$.

In Sections 2-3, we use the Leray-Schauder degree to seek positive solutions of (1.1) subject to one of $(1.2 \mathrm{a})^{\prime},(1.2 \mathrm{~b})^{\prime}$ and $(1.2 \mathrm{c})^{\prime}$. All the results obtained in Sections $2-3$ can be applied to obtain the existence of a positive radial solution of (1.1).

2.

In this section we establish the existence of positive solutions on $\left[t_{0}, t_{1}\right]$ of

$$
\left\{\begin{array}{l}
u^{\prime \prime}+\phi(t) g\left(t, u, u^{\prime}(t)\right)=0 \\
u\left(t_{0}\right)=0, u^{\prime}\left(t_{1}\right)=b \geqq 0
\end{array}\right.
$$

where $t_{0}>0, \phi(t)$ is as in (1.4).

Theorem 2.1. Suppose that

(i) $g$ is continuous on $\left[t_{0}, t_{1}\right] \times(0, \infty) \times(-\infty, \infty)$;

(ii) $0<g(t, u, z) \leqq \psi(t) h(u)$ on $\left(t_{0}, t_{1}\right) \times(0, \infty) \times(-\infty, \infty)$, where

(a) $h(u)>0$ is continuous and nonincreasing on $(0, \infty)$,

(b) $\psi>0$ is continuous on $\left[t_{0}, t_{1}\right]$,

(c) $1 / h\left(k\left(t-t_{0}\right)\right)$ is continuous on $\left[t_{0}, t_{1}\right]$ for each constant $k, 0<k<1$.

(d) $\int_{t_{0}}^{t_{1}} h\left(k\left(t-t_{0}\right)\right) \psi(t) d t<\infty$ for any constant $k, 0<k<1$,

(e) $\lim _{t \rightarrow \infty} h(t) \int_{1}^{t}[h(s)]^{-1} d s=\infty$.

(iii) for each constant $M_{0}>0$ there exists $\xi(t)$ continuous on $\left[t_{0}, t_{1}\right]$ and positive on $\left(t_{0}, t_{1}\right)$ such that $g(t, u, z) \geqq \xi(t)$ on $\left[t_{0}, t_{1}\right] \times\left(0, M_{0}\right] \times(-\infty, \infty)$. Then Problem $(2.1)$ has a positive solution.

Example 1. Let $g(t, u, z)=t^{-2} u^{-1 / 2}\left(1+3 u^{1 / 2}\right)\left(2+z^{2}\right)\left(1+z^{2}\right)^{-1}$ and $\xi(t)=3 t^{-2}$. We let $h(u)=u^{-1 / 2}\left(1+3 u^{1 / 2}\right), \psi(t)=2 t^{-2}$, an easy calculation shows that $g(t, u, z), h(u)$ and $\xi(t)$ satisfy all the conditions of Theorem 1 . Therefore, the equation

$$
\Delta u+\left[(N-2) r^{N-2}\right]^{2} u^{-1 / 2}\left(1+3 u^{1 / 2}\right)\left[2+r^{2(N-1)}\left(u^{\prime}(r)\right)^{2}\right]\left[1+r^{2(N-1)}\left(u^{\prime}(r)\right)^{2}\right]^{-1}=0
$$

for $r \in\left[R_{1}, R_{0}\right]$ with the boundary condition (1.2c) has a positive radially symmetric solution.

Example 2. Let $g(t, u, z)=\left(t-t_{0}\right)^{2} u^{-5 / 2}\left(3+z^{2}\right)\left(1+z^{2}\right)^{-1}, \quad \xi(t)=M_{0}^{-5 / 2}\left(t-t_{0}\right)^{2}$, where $M_{0}$ is as in (iii). Let $h(u)=u^{-s / 2}, \psi(t)=3\left(t-t_{0}\right)^{2}$, we obtain from Theorem 2.1 that the equation

$$
\Delta u+(N-2)^{2}\left[r^{-(N-2)}-R_{0}^{-(N-2)}\right]^{2} u^{-5 / 2}\left[3+r^{2(N-1)}\left(u^{\prime}(r)\right)^{2}\right]\left[1+r^{2(N-1)}\left(u^{\prime}(r)\right)^{2}\right]^{-1}=0
$$


for $r \in\left[R_{1}, R_{0}\right]$ with the boundary condition (1.2c) has a positive radially symmetric solution.

\section{Proof of Theorem 2.1.}

We consider the problem:

$$
\left\{\begin{array}{l}
u^{\prime \prime}+\phi(t) g\left(t, u, u^{\prime}\right)=0 \\
u\left(t_{0}\right)=1 / n, u^{\prime}\left(t_{1}\right)=b \geqq 0
\end{array}\right.
$$

where $\mathrm{n} \in \mathbb{N}=\{1,2,3, \ldots\}$ to avoid the possible singularity of $g$ at $u=0$. If $u$ is any solution to (2.2), then $u^{\prime \prime}<0$ on $\left(t_{0}, t_{1}\right)$. So, $u^{\prime}>b \geqq 0$ on $\left(t_{0}, t_{1}\right)$ which implies that $u$ is strictly increasing on $\left(t_{0}, t_{1}\right)$. Accordingly, we may remove the singularity at $u=0$ by defining

$$
g_{n}(t, u, z)= \begin{cases}g(t,|u|, z), & t_{0}<t<t_{1},|u| \geqq 1 / n \\ g(t, 1 / n, z), & t_{0}<t<t_{1},|u|<1 / n\end{cases}
$$

So, every solution $v$ of

$$
\left\{\begin{array}{l}
v^{\prime \prime}+\phi(t) g_{n}\left(t, v, v^{\prime}\right)=0 \\
v\left(t_{0}\right)=1 / n, v^{\prime}\left(t_{1}\right)=b
\end{array}\right.
$$

is a solution to (2.2). We now consider the family of problems

$$
\left\{\begin{array}{l}
u^{\prime \prime}+(1-\lambda) \delta+\lambda \phi(t) g_{n}\left(t, u, u^{\prime}\right)=0 \\
u\left(t_{0}\right)=1 / n, u^{\prime}\left(t_{1}\right)=b
\end{array}\right.
$$

where $0<\delta<1$ is a positive real number which is determined below and $\lambda \in[0,1]$. Let $u(t)$ be a solution of $(2.4)_{\lambda}^{n}$, then $u(t) \geqq 1 / n, u^{\prime}(t) \geqq b$ for $t \in\left[t_{0}, t_{1}\right]$. We also have $u^{\prime \prime}+(1-\lambda) \delta+\lambda \phi(t) \psi(t) h(u) \geqq u^{\prime \prime}+(1-\lambda) \delta+\lambda \phi(t) g_{n}\left(t, u, u^{\prime}\right)=0$ and this implies $-u^{\prime \prime} \leqq(1-\lambda) \delta+\lambda \phi(t) \psi(t) h(u)$. Integrating from $t$ to $t_{1}$ we obtain

$$
u^{\prime}(t)-b \leqq(1-\lambda) \delta\left(t_{1}-t_{0}\right)+\lambda \int_{t}^{t_{1}} \phi(s) \psi(s) h(u(s)) d s \leqq \delta\left(t_{1}-t_{0}\right)+h(u(t)) \int_{t_{0}}^{t_{1}} \phi(s) \psi(s) d s,
$$

since $h$ is nonincreasing. Thus,

$$
u^{\prime}(t) \leqq \delta\left(t_{1}-t_{0}\right)+h(u(t)) \int_{t_{0}}^{t_{1}} \phi(s) \psi(s) d s+b
$$

Dividing by $h(u(t))$ and integrating from $t_{0}$ to $t$ we obtain 


$$
\int_{1 / n}^{u(t)} \frac{d v}{h(v)} \leqq\left[\delta\left(t_{1}-t_{0}\right)+b\right] \frac{\left(t_{1}-t_{0}\right)}{h(u(t))}+\left(t_{1}-t_{0}\right) \int_{t_{0}}^{t_{1}} \phi(t) \psi(t) d t
$$

It follows from (e) that there exists a constant $C_{0}>0$ which is independent of $\lambda, \delta, n$, such that

$$
u(t) \leqq C_{0} \quad t \in\left[t_{0}, t_{1}\right]
$$

therefore $1 / n \leqq u(t) \leqq C_{0}$. On the other hand, from $u^{\prime \prime}(t) \leqq-(1-\lambda) \delta-\lambda \phi(t) \xi(t)$, we obtain $u(t) \geqq \theta(t)+1 / n$, where

$$
\theta(t)=b\left(t-t_{0}\right)+2^{-1}(1-\lambda) \delta\left(2 t_{1}-t_{0}-t\right)\left(t-t_{0}\right)+\lambda \int_{t_{0}}^{t} \int_{s}^{t_{1}} \phi(v) \xi(v) d v d s
$$

Let

$$
\zeta(t)=\int_{t_{0}}^{t} \int_{s}^{t_{1}} \phi(v) \xi(v) d v d s
$$

and

$$
k_{0}=\int_{t_{0}}^{t_{1}} \phi(s) \xi(s) d s
$$

then $\zeta^{\prime}\left(t_{0}\right)=k_{0}>0$. Hence there is an $\varepsilon>0$ such that $\zeta(t) \geqq 2^{-1} k_{0}\left(t-t_{0}\right)$ on $\left[t_{0}, t_{0}+\varepsilon\right]$. Since $\zeta(t) /\left(t-t_{0}\right)$ is bounded below on $\left[t_{0}+\varepsilon, t_{1}\right]$, there is a constant $k_{1}>0$ such that $\zeta(t) \geqq k_{1}\left(t-t_{0}\right)$ on $\left[t_{0}+\varepsilon, t_{1}\right]$. Let $k=\min \left\{k_{0} / 2, k_{1}\right\}$, therefore,

$$
1 / n+\left[b+2^{-1}(1-\lambda) \delta\left(t_{1}-t_{0}\right)+\lambda \bar{k}\right]\left(t-t_{0}\right) \leqq u(t) \leqq C_{0} .
$$

Let $0<\delta<\min \left\{\left(t_{1}-t_{0}\right)^{-1}, \bar{k}\left(t_{1}-t_{0}\right)^{-1}, 1\right\}$. We obtain

$$
1 / n+\left[2^{-1} \delta\left(t_{1}-t_{0}\right)\right]\left(t-t_{0}\right) \leqq u(t) \leqq C_{0}
$$

Using $\left|u^{\prime \prime}(t)\right| \leqq 1+\phi(t) \psi(t) h(u(t))$, we know that

$$
\left|u^{\prime \prime}\right| \leqq 1+\phi(t) \psi(t) h\left(\left[2^{-1} \delta\left(t_{1}-t_{0}\right)\right]\left(t-t_{0}\right)\right),
$$

and then

$$
\left|u^{\prime}(t)\right| \leqq b+\left(t_{1}-t_{0}\right)+\int_{t_{0}}^{t_{1}} \phi(t) \psi(t) h\left(\left[2^{-1} \delta\left(t_{1}-t_{0}\right)\right]\left(t-t_{0}\right)\right) d t=C_{1}
$$

where $C_{1}>0$ is independent of $\lambda, n$. Let $x(t)=1 / h\left(\left[2^{-1} \delta\left(t_{1}-t_{0}\right)\right]\left(t-t_{0}\right)\right)$, then 


$$
\left|x(t) u^{\prime \prime}(t)\right| \leqq x(t)+\phi(t) \psi(t) \leqq C_{2}
$$

For $u \in C^{2}\left(t_{0}, t_{1}\right) \cap C^{1}\left[t_{0}, t_{1}\right]$ define

$$
\begin{aligned}
& \|u\|_{0}=\sup _{\left[t_{0}, t_{1}\right]}|u(t)| \\
& \|u\|_{1}=\max \left(\|u\|_{0},\left\|u^{\prime}\right\|_{0}\right) \\
& \|u\|_{2}=\max \left(\|u\|_{0},\left\|u^{\prime}\right\|_{0}, \sup _{\left[t_{0}, t_{1}\right]}\left|x(t) u^{\prime \prime}(t)\right|\right) .
\end{aligned}
$$

Set

$$
\mathbb{K}_{a, b}=\left\{u \in C^{2}\left(t_{0}, t_{1}\right) \cap C^{1}\left[t_{0}, t_{1}\right] u\left(t_{0}\right)=a \geqq 0, u^{\prime}\left(t_{1}\right)=b \geqq 0 \text { and }\|u\|_{2}<\infty\right\}
$$

with norm $\|\cdot\|_{2}$ and

$$
\mathbb{C}=\left\{u \in C\left(t_{0}, t_{1}\right): \sup _{\left[t_{0}, t_{1}\right]}|u(t)|<\infty\right\}
$$

with the obvious norm. We know that $\mathbb{K}_{a, b}$ and $\mathbb{C}$ are Banach spaces (see [3]). Define mappings $G_{\lambda, n}: C^{1}\left[t_{0}, t_{1}\right] \rightarrow \mathbb{C}, \quad j: \mathbb{K}_{1 / n, b} \rightarrow C^{1}\left[t_{0}, t_{1}\right], \quad L: \mathbb{K}_{1 / n, b} \rightarrow \mathbb{C}$ by $G_{\lambda, n}(u)(t)=$ $x(t)\left[(1-\lambda) \delta+\lambda \phi(t) g_{n}\left(t, u, u^{\prime}\right)\right], j u=u$, and $L u=x(t) u^{\prime \prime}(t)$. Clearly $G_{\lambda, n}$ is continuous by the continuity of $x(t) g_{n}$. By the same idea as in [3], [17] we know that $j$ is completely continuous and $L^{-1}$ exists and is continuous. Now, $(2.4)_{\lambda}^{\mathrm{n}}$ is equivalent to

$$
\left(I+L^{-1} G_{\lambda, n} j\right)(u)=0 .
$$

Let

$$
C=\max \left\{C_{0}, C_{1}, C_{2}, 1+b\left(t_{1}-t_{0}\right)+\delta\left(t_{1}-t_{0}\right)^{2}, \delta \max _{\left[t_{0}, t_{1}\right]}(x(t)), b+\delta\left(t_{1}-t_{0}\right)\right\}
$$

and define

$$
U=\left\{u \in \mathbb{K}_{1 / n, b},\|u\|_{2}<C+1\right\},
$$

then $\left(I+L^{-1} G_{\lambda, n} j\right)(u) \neq 0$ on $\partial U$. Finally, by $1 / n+b\left(t-t_{0}\right)+2^{-1} \delta\left(2 t_{1}-t_{0}-t\right)\left(t-t_{0}\right) \in U$ and properties of the Leray-Schauder degree, we have

$$
\operatorname{deg}\left(I+G_{1, n} j, U, 0\right)=1
$$

Then (2.3) has a solution in $U$. The remainder of the proof is similar to the proof of Theorem 1 of [3]. 
Remark 1. The results of Theorem 1 extend the results of [3], [17]. In [17], one of the conditions on $h(u)$ is $\int_{0}^{c} h(s) d s<\infty, c \in[0, \infty)$. So, for example, no result of [17] applies to Example 2 above.

Theorem 2.2. Suppose that

(i) $g$ is continuous on $\left(t_{0}, t_{1}\right) \times(0, \infty) \times(0, \infty)$,

(ii) $\xi(t) \leqq g(t, u, z) \leqq \psi(t) h(u) p(z)$ on $\left(t_{0}, t_{1}\right) \times(0, \infty) \times(0, \infty)$,

where

(a) $h(u)>0, p(z)>0$ are continuous and nonincreasing on $(0, \infty)$,

(b) $\psi(t)>0$ and $\xi(t)>0$ are continuous on $\left(t_{0}, t_{1}\right) ; \xi\left(t_{1}\right)>0$ and $\int_{t_{0}}^{t_{1}} \xi(t) d t<\infty$,

(c) $\int_{t_{0}}^{t_{1}} \psi(t) h\left(\alpha\left(t-t_{0}\right)\right) p\left(\beta\left(t_{1}-t\right)\right) d t<\infty$, for each pair $(\alpha, \beta), 0<\alpha, \beta<1$,

(d) $g(t, u, z) /\left[\psi(t) h\left(\alpha\left(t-t_{0}\right)\right) p\left(\beta\left(t_{1}-t\right)\right)\right],\left[\psi(t) h\left(\alpha\left(t-t_{0}\right)\right) p\left(\beta\left(t_{1}-t\right)\right)\right]^{-1}$ are continuous on $\left[t_{0}, t_{1}\right] \times(0, \infty) \times(0, \infty)$ and $\left[t_{0}, t_{1}\right]$ respectively for $\alpha, \beta, 0<\alpha, \beta<1$. Then Problem (2.l) has a positive solution.

Example 3. Let $g(t, u, z)=\psi(t) h(u) p(z)$; here $\psi(t)=t, h(u)=u^{-3 / 4}\left(1+u^{3 / 4}\right)$ and

$$
p(z)= \begin{cases}z^{-1 / 2}, & 0<z \leqq 1 \\ \frac{1}{2}\left(1+z^{-4 / 5}\right), & z>1\end{cases}
$$

Let $\xi(t)=t / 2$. A calculation shows that the functions satisfy the conditions of Theorem 2.2 .

\section{Proof of Theorem 2.2.}

We only discuss the case when $u^{\prime}\left(t_{1}\right)=b=0$. For $b \neq 0$ this theorem follows easily from the proof of Theorem 2.1. We consider the family of problems

$$
\left\{\begin{array}{l}
u^{\prime \prime}+(1-\lambda) \delta+\lambda \phi(t) g_{n}\left(t, u, u^{\prime}\right)=0 \\
u\left(t_{0}\right)=1 / n, u^{\prime}\left(t_{1}\right)=1 / n
\end{array}\right.
$$

where

$$
g_{n}(t, u, z)= \begin{cases}g(t,|u|,|z|), & t_{0}<t<t_{1},|u| \geqq 1 / n,|z| \geqq 1 / n \\ g(t, 1 / n, 1 / n), & t_{0}<t<t_{1},|u|<1 / n,|z|<1 / n\end{cases}
$$

$0<\delta<1$ is determined below and $\lambda \in[0,1]$. Let $u$ be a solution of $(2.18)_{\lambda}^{\mathrm{n}}$, then $u(t) \geqq 1 / n$, $u^{\prime}(t) \geqq 1 / n$, for $t \in\left[t_{0}, t_{1}\right]$. It follows from (ii) that $u(t) \geqq \theta(t)+1 / n$ and $u^{\prime}(t) \geqq \theta^{\prime}(t)+1 / n$, where 


$$
\begin{gathered}
\theta(t)=2^{-1}(1-\lambda) \delta\left(2 t_{1}-t_{0}-t\right)\left(t-t_{0}\right)+\lambda \int_{t_{0}}^{t} \int_{s}^{t_{1}} \phi(v) \xi(v) d v d s, \\
\theta^{\prime}(t)=(1-\lambda) \delta\left(t_{1}-t\right)+\lambda \int_{1}^{t_{1}} \phi(s) \xi(s) d s \\
\theta^{\prime \prime}\left(t_{1}\right)=-(1-\lambda) \delta-\lambda \phi\left(t_{1}\right) \xi\left(t_{1}\right) .
\end{gathered}
$$

Then, there exists a $C_{3}>0$ such that $\int_{t_{0}}^{t_{1}} \phi(s) \xi(s) d s>C_{3}$ and

$$
\theta^{\prime}\left(t_{0}\right) \geqq(1-\lambda) \delta\left(t_{1}-t_{0}\right)+\lambda C_{3}
$$

Using the same methods as in the proof of Theorem 2.1, we have that there exists a constant $k_{2}, 0<k_{2}<1$ such that

$$
u(t) \geqq k_{2}\left(t-t_{0}\right) \text { for } t \in\left(t_{0}, t_{1}\right)
$$

Whether $\xi\left(t_{1}\right)=\infty$ or not, there exists a constant $C_{4}>0$ such that $\phi\left(t_{1}\right) \xi\left(t_{1}\right)>C_{4}$, and

$$
\theta^{\prime \prime}\left(t_{1}\right) \leqq-(1-\lambda) \delta-\lambda C_{4}
$$

Using the same idea as above, we have that there exists a constant $k_{3}, 0<k_{3}<1$ such that

$$
\theta^{\prime}(t) \geqq k_{3}\left(t_{1}-t\right), \quad \text { for } \quad t \in\left(t_{0}, t_{1}\right) \text {. }
$$

Therefore, $u^{\prime}(t) \geqq k_{3}\left(t_{1}-t\right)+1 / n$ and $\left|u^{\prime \prime}(t)\right| \leqq 1+\phi(t) \psi(t) h\left(k_{2}\left(t-t_{0}\right)\right) p\left(k_{3}\left(t_{1}-t\right)\right)$. Hence, by conditions $(c)$,

$$
\left|u^{\prime}(t)\right| \leqq\left(t_{1}-t_{0}\right)+\int_{t_{0}}^{t_{1}} \phi(t) \psi(t) h\left(k_{2}\left(t-t_{0}\right)\right) p\left(k_{3}\left(t_{1}-t\right)\right) d t=C_{5}
$$

and

$$
|u(t)| \leqq C_{6} \quad \text { for } \quad t \in\left[t_{0}, t_{1}\right] .
$$

$C_{6}=C_{5}\left(t_{1}-t_{0}\right)$. Let $x(t)=\left[\psi(t) h\left(k_{2}\left(t-t_{0}\right)\right) p\left(k_{3}\left(t_{1}-t\right)\right)\right]^{-1}$, then, $\left|x(t) u^{\prime \prime}(t)\right| \leqq x(t)+\phi(t) \leqq$ $C_{7}$. Here $C_{5}, C_{6}$ and $C_{7}$ are positive constants which are independent of $\lambda, n$. The remainder of the proof is similar to the proofs of Theorem 2.1 .

If $g(t, u, z)$ has singularities at $t=t_{0}, t=t_{1}$ and $\lim _{u \rightarrow \infty} g(t, u, z)=0$ for $(t, z) \in\left(t_{0}, t_{1}\right) \times$ $(-\infty, \infty)$, then the condition (ii) of Theorem 2.2 does not hold. In this case the following theorem applies:

\section{Theorem 2.3. Suppose that}


(i) $g$ is continuous on $\left(t_{0}, t_{1}\right) \times(0, \infty) \times(-\infty, \infty)$;

(ii) $0<g(t, u, z) \leqq \psi(t) h(u)$ on $\left(t_{0}, t_{1}\right) \times(0, \infty) \times(-\infty, \infty)$, where
(a) $h>0$ is continuous and nonincreasing on $(0, \infty)$,
(b) $\psi>0$ is continuous on $\left(t_{0}, t_{1}\right)$ and $\int_{t_{0}}^{t_{1}}\left(t-t_{0}\right) \psi(t) d t<\infty$,
(c) $g(t, u, z) /\left[\psi(t) h\left(k\left(t-t_{0}\right)\right)\right]$ and $1 /\left[\psi(t) h\left(k\left(t-t_{0}\right)\right)\right]$ are continuous on $\left[t_{0}, t_{1}\right] \times$ $(0, \infty) \times(-\infty, \infty)$ and $\left[t_{0}, t_{1}\right]$ respectively, for each constant $k, 0<k<1$.
(d) $\int_{t_{0}}^{t_{1}} h\left(k\left(t-t_{0}\right)\right) \psi(t) \phi(t) d t<\infty$ for any constant $k, 0<k<1$,
(e) $\lim _{t \rightarrow \infty} h(t) \int_{1}^{t}[h(s)]^{-1} d s=\infty$.

(iii) For each constant $M_{0}>0$ there exists $\xi(t)>0$ continuous on $\left(t_{0}, t_{1}\right)$ and $\int_{t_{0}}^{t_{1}}\left(t-t_{0}\right) \xi(t) d t<\infty$, such that $g(t, u, z) \geqq \xi(t)$ on $\left(t_{0}, t_{1}\right) \times\left(0, M_{0}\right] \times(-\infty, \infty)$. Then Problem (2.l) has a positive solution.

Proof. Let $x(t)=\left\{\psi(t) h\left(\left[2^{-1} \delta\left(t_{1}-t_{0}\right)\right]\left(t-t_{0}\right)\right)\right\}^{-1}$ be as in Theorem 2.1, then the result of this theorem follows from a slight modification of the proof of Theorem 2.1 by changing the order of integration (see [3], [11]).

If $g(t, u, z)$ has singularities at $t=t_{0}, t=t_{1}$ and $\lim _{z \rightarrow \infty} g(t, u, z)=0$ for $(t, u) \in\left(t_{0}, t_{1}\right) \times$ $(0, \infty)$, then the following theorem applies:

Theorem 2.4. Suppose that

(i) $g$ is continuous on $\left(t_{0}, t_{1}\right) \times[0, \infty) \times(0, \infty)$,

(ii) $0<g(t, u, z) \leqq \psi(t) p(z)$ on $\left(t_{0}, t_{1}\right) \times(0, \infty) \times(0, \infty)$, where

(a) $p(z)>0$ is continuous and nonincreasing on $(0, \infty)$ and $z p(z)$ is nondecreasing on $(0, \infty)$,

(b) $\psi(t)>0$ is continuous on $\left(t_{0}, t_{1}\right)$ and $\int_{t_{0}}^{t_{1}} \psi(t) d t<\infty$,

(c) $g(t, u, z) /\left[\psi(t) p\left(k\left(t_{1}-t\right)\right)\right]$ is continuous on $\left[t_{0}, t_{1}\right] \times[0, \infty) \times(0, \infty)$ for each constant $k>0$,

(iii) for constants $M_{1}, M_{2}>0$ there exists a continuous, positive function $\xi(t)$ on $\left(t_{0}, t_{1}\right)$ and $\int_{t_{0}}^{t_{1}} \xi(t) d t<\infty$ such that $g(t, u, z) \geqq \xi(t)$ on $\left(t_{0}, t_{1}\right) \times\left(0, M_{1}\right] \times\left(0, M_{2}\right]$. Then Problem (2.l) has a positive solution.

Proof. We only discuss the case when $u^{\prime}\left(t_{1}\right)=b=0$. We consider the family of problems

$$
\left\{\begin{array}{l}
u^{\prime \prime}+\lambda \phi(t) g_{n}\left(t, u, u^{\prime}\right)=0 \\
u\left(t_{0}\right)=1 / n, u^{\prime}\left(t_{1}\right)=1 / n
\end{array}\right.
$$

Here $g_{n}\left(t, u, u^{\prime}\right), \lambda$ are as in the proof of Theorem 2.2. Let $u$ be a solution of $(2.27)_{\lambda}^{\mathrm{n}}$, then $u(t) \geqq 1 / n$ and $u^{\prime}(t) \geqq 1 / n$, for $t \in\left[t_{0}, t_{1}\right]$. From (ii) we know that $\left(1 / p\left(u^{\prime}(t)\right)\right) u^{\prime \prime}(t)+$ $\lambda \phi(t) \psi(t) \geqq 0$. Let 


$$
f(z)=\int_{0}^{z} \frac{d z}{p(z)}
$$

$f(z)$ is increasing since $p(z)$ is decreasing and $\left(f\left(u^{\prime}(t)\right)\right)^{\prime}+\lambda \phi(t) \psi(t) \geqq 0$. Therefore,

$$
f\left(u^{\prime}(t)\right) \leqq f(1 / n)+\int_{t_{0}}^{t_{1}} \phi(t) \psi(t) d t
$$

The fact that $f(z)$ is increasing and condition (b) together imply that $\left|u^{\prime}(t)\right| \leqq C_{8}$ and $|u(t)| \leqq C_{8}\left(t_{1}-t_{0}\right)$. Let $C_{9}=C_{8}\left(t_{1}-t_{0}\right)$. Then $C_{8}$ and $C_{9}$ are independent of $\lambda, n$. By condition (iii) and the same idea as in the proof of Theorem 2.2, we have that there exists $k_{4}>0$ such that $u^{\prime}(t) \geqq \lambda k_{4}\left(t_{1}-t\right)$ and

$$
\left|u^{\prime \prime}(t)\right| \leqq \lambda \phi(t) \psi(t) p\left(\lambda k_{4}\left(t_{1}-t\right)\right) \leqq \phi(t) \psi(t) p\left(k_{4}\left(t_{1}-t\right)\right)
$$

Let $x(t)=1 /\left[\psi(t) p\left(k_{4}\left(t_{1}-t\right)\right)\right]$. Define $\mathbb{K}_{1 / n, 1 / n}, L, j, G_{\lambda, n}$ as in Theorem 2.1 for $\delta=0$, the proof is then a consequence of Leray-Schauder degree theory as in the proof of Theorem 2.1.

Remark 2. By the same methods we can discuss the following problem

$$
\left\{\begin{array}{l}
u^{\prime \prime}+\phi(t) g\left(t, u, u^{\prime}\right)=0 \\
u^{\prime}\left(t_{0}\right)=0, u\left(t_{1}\right)=0
\end{array}\right.
$$

and obtain results similar to the above theorems.

3.

In this section we examine the existence of positive solutions on $\left(t_{0}, t_{1}\right)\left(t_{0}>0\right)$ to

$$
\left\{\begin{array}{l}
u^{\prime \prime}+\phi(t) g\left(t, u, u^{\prime}\right)=0 \\
u\left(t_{0}\right)=u\left(t_{1}\right)=0
\end{array}\right.
$$

Theorem 3.1. Suppose that

(i) $g$ is continuous on $\left(t_{0}, t_{1}\right) \times(0, \infty) \times(-\infty, \infty)$;

(ii) $0<g(t, u, z) \leqq \psi(t) h(u)$ on $\left(t_{0}, t_{1}\right) \times(0, \infty) \times(-\infty, \infty)$, where

(a) $h(u)$ is continuous and nonincreasing on $(0, \infty)$,

(b) $\psi>0$ is continuous on $\left(t_{0}, t_{1}\right)$ and $\int_{t_{0}}^{t_{1}}\left(t_{1}-t\right)\left(t-t_{0}\right) \psi(t) d t<\infty$,

(c) $g(t, u, z) /\left[\psi(t) h\left(k\left(t-t_{0}\right)\left(t_{1}-t\right)\right)\right] \in C^{0}\left(\left[t_{0}, t_{1}\right] \times(0, \infty) \times(-\infty, \infty)\right)$, for each constant $k, 0<k<1$, 
(d) $\int_{t_{0}}^{t_{1}} \psi(t) h\left(k\left(t-t_{0}\right)\left(t_{1}-t\right)\right) d t<\infty$ for any constant $k, 0<k<1$,

(e) $\lim _{t \rightarrow \infty} h(t) \int_{1}^{t}[h(s)]^{-1} d s=\infty$.

(iii) for each constant $M_{0}>0$ there exists a continuous and positive function $\xi(t)$ on $\left(t_{0}, t_{1}\right), \int_{t_{0}}^{t_{1}}\left(t-t_{0}\right)\left(t_{1}-t\right) \xi(t) d t<\infty$ such that

$$
g\left(t, u, u^{\prime}\right) \geqq \xi(t) \text { on }\left(t_{0}, t_{1}\right) \times\left(0, M_{0}\right] \times(-\infty, \infty)
$$

Then Problem (3.1) has a positive solution.

Proof. Use the same idea as in the proof of Theorem 1 of [11].

Theorem 3.2. Suppose that

(i) $g(t, u, z)$ is continuous on $\left[t_{0}, t_{1}\right] \times(0, \infty) \times(0, \infty)$;

(ii) $\xi(t) \leqq g(t, u, z) \leqq \psi(t) h(u) p(z)$ on $\left[t_{0}, t_{1}\right] \times(0, \infty) \times(0, \infty)$, where

(a) $h>0, p>0$ are continuous and nonincreasing on $(0, \infty), \lim _{z \rightarrow 0} p(z)=\infty$,

(b) $\xi(t)>0, \psi(t)>0$ are continuous on $\left[t_{0}, t_{1}\right], \xi>0$ at $t=t_{0}, t_{1}$,

(c) $\int_{t_{0}}^{t_{0}+\varepsilon} \psi(t) h\left(k\left(t-t_{0}\right)\right) d t<\infty ; \quad \int_{t_{1}-\varepsilon}^{t_{1}} \psi(t) h\left(k\left(t_{1}-t\right)\right) d t<\infty ; \quad \int_{0}^{\varepsilon} p(t) d t<\infty$, for each constant $\varepsilon, k, 0<\varepsilon, k<1$,

(d) $1 / h\left(k\left(t_{1}-t\right)\right.$ and $1 / h\left(k\left(t-t_{0}\right)\right)$ are continuous on $\left[t_{0}, t_{1}\right]$. Then problem

$$
\left\{\begin{array}{l}
u^{\prime \prime}+\phi(t) g\left(t, u,\left|u^{\prime}\right|\right)=0 \\
u\left(t_{0}\right)=u\left(t_{1}\right)=0
\end{array}\right.
$$

has a positive solution in $C^{2}\left(t_{0}, t_{1}\right) \cap C^{1}\left[t_{0}, t_{1}\right]$.

Proof. We consider the family of problems

$$
\left\{\begin{array}{l}
u^{\prime \prime}+(1-\lambda) \delta+\lambda \phi(t) g_{n}\left(t, u+1 / n, u^{\prime}\right)=0 \\
u\left(t_{0}\right)=u\left(t_{1}\right)=0
\end{array}\right.
$$

Here $g_{n}\left(t, u, u^{\prime}\right)$ is as in the proof of Theorem 2.2. Let $u$ be a solution of $(3.3)_{\lambda}^{n}$, then $u \geqq 0$ for $t \in\left[t_{0}, t_{1}\right]$. Let $t_{2} \in\left(t_{0}, t_{1}\right), u\left(t_{2}\right)=\max _{t_{0}<t<t_{1}} u(t)$. By the proof of Theorem 2.2, we know that there exist $k_{5}, k_{6}$ satisfying $0<k_{5}, k_{6}<1$ such that $u(t) \geqq k_{5}\left(t-t_{0}\right), u^{\prime}(t) \geqq$ $k_{6}\left(t_{2}-t\right)$ for $t \in\left[t_{0}, t_{2}\right]$. A similar argument on $\left[t_{2}, t_{1}\right]$ yields $u(t) \geqq k_{7}\left(t_{1}-t\right),\left|u^{\prime}(t)\right| \geqq$ $k_{8}\left(t-t_{2}\right)$ for $t \in\left[t_{2}, t_{1}\right]$. Here, $0<k_{7}, k_{8}<1$. Then,

$$
\left|u^{\prime \prime}(t)\right| \leqq(1-\lambda) \delta+\lambda \phi(t) \psi(t) h(u) p\left(\left|u^{\prime}\right|\right) \leqq \begin{cases}1+\phi(t) \psi(t) h\left(k_{5}\left(t-t_{0}\right)\right) p\left(k_{6}\left(t_{2}-t\right)\right), & t \in\left(t_{0}, t_{2}\right) \\ 1+\phi(t) \psi(t) h\left(k_{7}\left(t_{1}-t\right)\right) p\left(k_{8}\left(t-t_{2}\right)\right), & t \in\left(t_{2}, t_{1}\right)\end{cases}
$$


Let

$$
x(t)= \begin{cases}1 / h\left(k_{5}\left(t-t_{0}\right)\right) p\left(k_{6}\left(t_{2}-t\right)\right), & t \in\left(t_{0}, t_{2}\right) \\ 1 / h\left(k_{7}\left(t_{1}-t\right)\right) p\left(k_{8}\left(t-t_{2}\right)\right), & t \in\left(t_{2}, t_{1}\right)\end{cases}
$$

By condition (d), $x \in C^{0}\left[t_{0}, t_{1}\right]$. Therefore,

$$
\left|x(t) u^{\prime \prime}(t)\right| \leqq C_{10}
$$

Condition (c) and (3.4) imply

$$
\left|u^{\prime}(t)\right| \leqq C_{11},|u(t)| \leqq C_{12}
$$

Here $C_{10}, C_{11}$ and $C_{12}$ are positive constants which are independent of $\lambda, n$ and $\delta$. The remainder of the proofs follows from a slight modification of the proof of Theorem 1 of [11].

Remark 3. It follows easily that the results of Theorems 2.3 and 3.2 still hold for $t_{0}=0$ if the function $m(t)=\phi(t) \psi(t)$ satisfies the conditions imposed on $\psi(t), n(t)=$ $\phi(t) \xi(t)$ satisfies the conditions imposed on $\xi(t)$. The result of Theorem 2.2 holds for $t_{0}=0$, if $m(t)$ satisfies the conditions imposed on $\psi(t)$ and $\int_{0}^{t_{1}} \phi(t) \xi(t) d t<\infty$. These results prove the existence of a positive radially symmetric solution $u$ of equation (1.1) in $\Omega=\left\{|x|,|x|>R_{1}\right\}$ and $u$ satisfies $\left.u\right|_{r=R 1}=0$ and $\lim _{r \rightarrow \infty} u(r)=0$.

Remark 4. Consider the following problem:

$$
\left\{\begin{array}{l}
u^{\prime \prime}+\lambda \phi(t) g_{n}\left(t, u+1 / n, u^{\prime}\right)=0 \\
u\left(t_{0}\right)=u\left(t_{1}\right)=0
\end{array}\right.
$$

Here $g_{n}\left(t, u, u^{\prime}\right)$ is as in Theorem 3.2. Using the same idea as in the proof of Theorem 3.2, we can obtain an existence result for Problem (3.2) if $g(t, u, z), \psi(t)$ and $p(z)$ satisfy all the conditions of Theorem 2.4 but $(c)$ replaced by

$$
(c)^{\prime} g(t, u, z) / \psi(t) \text { is continuous on }\left[t_{0}, t_{1}\right] \times[0, \infty) \times(0, \infty) \text {. }
$$

We also need $\lim _{z \rightarrow 0} p(z)=\infty$.

Remark 5. By the results obtained in [17], we prove the existence of positive radial solutions of (1.1) subject to one of the following sets of boundary conditions

$$
\begin{array}{lll}
u=a \geqq 0 \quad \text { on } r=R_{1} \quad \text { and } \quad u=b \geqq 0 \quad \text { on } r=R_{0} \\
u=\alpha \geqq 0 \quad \text { on } r=R_{1} \quad \text { and } \quad \frac{\partial}{\partial r}=b>0 \quad \text { on } t=R_{0}
\end{array}
$$




$$
\frac{\partial u}{\partial r}=a>0 \quad \text { on } r=R_{1} \quad \text { and } \quad u=b \geqq 0 \quad \text { on } r=R_{0}
$$

where $0<R_{1}<R_{0} \leqq \infty$

Acknowledgements. The author would like to thank Professor J. R. L. Webb for helpful discussions and corrections. He also thanks the referee for valuable suggestions.

\section{REFERENCES}

1. A. Ambrosetti and P. H. Rabinowitz, Dual variational methods in critical point theory and applications, J. Funct. Anal. 14 (1973), 349-381.

2. C. Bandle, C. V. Coffman and M. Marcus, Nonlinear elliptic problems in annular domains, J. Differential Equations 69 (1987), 322-345.

3. L. E. Bobisud, D. O'Regan and W. D. Royalty, Solvability of some nonlinear boundary value problems, Nonlinear Analysis, T. M. A. 12(9) (1988), 855-869.

4. H. Brezis and E. L. Turner, On a class of superlinear elliptic problems, Comm. Partial Differential Equations 2 (1977), 601-614.

5. C. V. Coffman, On the positive solutions of boundary value problems for a class of nonlinear differential equations, J. Differential Equations 3 (1967), 92-111.

6. X. Garaizer, Existence of positive radial solutions for semilinear elliptic equations in the annulus, J. Differential Equations 70 (1987), 69-92.

7. J. A. Gatica, V. Oliker and P. Waltman, Singular nonlinear boundary value problems for second order ordinary differential equations, J. Differential Equations 79 (1989), 62-78.

8. I. M. Gelfand, Some problems in the theory of quasilinear equations, Amer. Math. Soc. Transl. 1(2) 29 (1963), 295-381.

9. B. Gidas, W. M. Nı and L. Nirenberg, Symmetry and related properties in almost spherically symmetric domains, Arch. Rat. Mech. Anal. 96 (1986), 167-197.

10. B. Gidas, W. M. N 1 and L. Nirenkerg, Symmetry and related properties via the maximum principle, Comm. Math. Phys. 68 (1979), 209-243.

11. Z. M. Guo, Solvability of some singular nonlinear boundary value problems and existence of positive radial solutions of some nonlinear elliptic problems, Nonlinear Analysis 16 (1991), 781-790.

12. S. S. LiN, On the existence of positive radial solutions for nonlinear elliptic equations in annular domains, J. Differential Equations 81 (1989), 221-223.

13. S. S. LiN, Positive radial solutions and non-radial bifurcation for semilinear elliptic equations in annulus domains, J. Differential Equations 86 (1990), 367-391.

14. P. L. Lions, On the existence of positive solutions of semilinear elliptic equations, SIAM Rev. 24 (1982), 441-467.

15. W. M. Nı, Uniqueness of solutions of nonlinear Dirichlet problems. J. Differential Equations 50 (1983), 289-304.

16. W. $M$. $\mathrm{N}_{\mathrm{I}}$ and $\mathrm{R}$. Nussbaum, Uniqueness and non-uniqueness for positive radial solutions of $\Delta u+f(u, r)=0$, Comm. Pure Appl. Math. 38 (1985), 67-108. 
17. D. O'Regan, Positive solutions to singular and non-singular second-order boundary value problems, J. Math. Anal. Appl. 142 (1989), 40-52.

18. S. I. Pohozaev, Eigenfunction of the equation $\Delta u+\lambda f(u)=0$, Soviet Math. Dokl. 5 (1965), 1408-1411.

Department of Mathematics

UNIVERSITY OF GLASGOW

Henan Normal University

GLASGOW G12 8QW

XINXIANG

SCOTLAND

P.R. China 